\title{
Correction: Irreversible aggregation of alternating tetra-block-like amphiphile in water
}

\section{The PLOS ONE staff}

Fig 1 is incorrect. The text box with numbers "18230006" should not appear in the figure. The publisher apologizes for the error. Please see the corrected Fig 1 here.

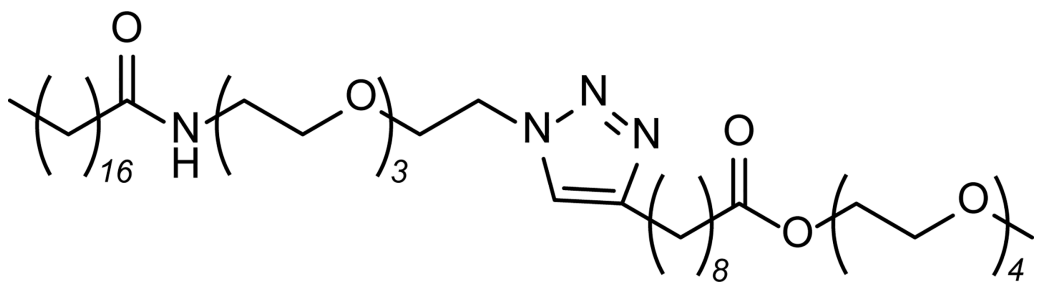

Fig 1. Scheme of alternating tetra-block-like amphiphile ATBA.

https://doi.org/10.1371/journal.pone.0205140.g001

\section{Reference}

1. Konno S, Banno T, Takagi $\mathrm{H}$, Honda S, Toyota $\mathrm{T}$ (2018) Irreversible aggregation of alternating tetrablock-like amphiphile in water. PLoS ONE 13(8): e0202816. https://doi.org/10.1371/journal.pone. 0202816 PMID: 30148887

\section{G openaccess}

Citation: The PLOS ONE staff (2018) Correction: Irreversible aggregation of alternating tetra-blocklike amphiphile in water. PLOS ONE 13(9): e0205140. https://doi.org/10.1371/journal. pone.0205140

Published: September 28, 2018

Copyright: @ 2018 The PLOS ONE staff. This is an open access article distributed under the terms of the Creative Commons Attribution License, which permits unrestricted use, distribution, and reproduction in any medium, provided the original author and source are credited. 